Portland State University

PDXScholar

$5-24-2019$

\title{
Idioms in Chinese EFL Contexts: a Review of 2004-2018
}

William Shanahan

Portland State University

Follow this and additional works at: https://pdxscholar.library.pdx.edu/honorstheses Let us know how access to this document benefits you.

\section{Recommended Citation}

Shanahan, William, "Idioms in Chinese EFL Contexts: a Review of 2004-2018" (2019). University Honors Theses. Paper 684.

https://doi.org/10.15760/honors.700

This Thesis is brought to you for free and open access. It has been accepted for inclusion in University Honors Theses by an authorized administrator of PDXScholar. Please contact us if we can make this document more accessible: pdxscholar@pdx.edu. 


\title{
Idioms in Chinese EFL Contexts: A Review of 2004-2018
}

\author{
By \\ William Shanahan \\ requirements for the degree of \\ Bachelor of Arts \\ in \\ University Honors \\ and \\ International Development Studies \\ Thesis Adviser \\ Dr. Kimberley Brown
}

An undergraduate honors thesis submitted in partial fulfillment of the

Portland State University 


\section{Abstract}

This paper reviews the discourse of 21 contemporary papers that focus on idioms in Chinese English as a Foreign Language (EFL) contexts. Key topics are identified: comprehension and retention, motivating factors, familiarity, and student perceptions. Common factors between the papers in each topic are analyzed, and some gaps in the literature identified. This paper further finds which common factors between papers are also common between multiple key topics. It seeks primarily to answer a single research question:

Where is the friction in the discourse between the East and the West, and how does it impact idiom EFL education in Chinese contexts?

The key topics are: comprehension and retention, etymological motivation, familiarity, and student perceptions. This paper finds remarkably little friction from Chinese researchers against Western ideas for idiom education. This paper concludes with some speculation as to why this is the case.

\section{Introduction}

While I was teaching English in China, working with adults studying English post-college, most of my students shared a common problem. They would understand the words a native English speaker had used, but not the meaning. After some puzzling, it became clear the constant offender was idiomatic expression. I added an idiom a day to my classes in an attempt to help my students. Sometimes this resulted in mass confusion. Other times the students all shouted the translation at once as the class collectively understood the idiom. But even given my 
occasional successes, I couldn't shake the feeling that there had to be a better way to teach idioms than asking my students to memorize an idiom a day.

As expected, Western educators do indeed propose a better method for teaching idioms to students in English as a Foreign Language (EFL) contexts. This method is generally called the Cognitive Linguistics Approach, which combines trends from the Communicative Approach from applied linguistics and psycholinguistics with a strong emphasis on second language acquisition (Robinson, 2008, p. 3-4). Broadly, the Cognitive Linguistic Approach teaches students to interpret idioms via their etymological motivations, which allows students to understand the idea behind a given idiom. Both the Communicative Approach and the Cognitive Linguistic Approach are Western contributions to applied linguistics pedagogy in EFL.

However there is a certain amount of friction between Western and Eastern methods as well as Western and Eastern researchers. The sociopolitical history of China in relation to the West is a litany of colonialism, anti-communism, and even simple miscommunication. One can understand that, given this context, the pressure of Western pedagogy towards China has not be gladly received, and may even fail to address the needs of the Chinese students it aims to help. Thus this research paper aims to answer the question:

Where is the friction in the discourse between the East and the West, and how does it impact idiom EFL education in Chinese contexts?

One would expect to see as much pushback against Western methods in idiom education as one sees in EFL pedagogy in general. This paper will answer the central research question by tracing EFL idiom education discourse and four specific aspects: comprehension and retention, motivating factors, familiarity, and student perceptions. 


\section{Background}

Tand and Absalom suggest that EFL teaching is largely started and driven by Western, English-speaking countries (1998, p. 119). The idea that Western methods are inherently better for the learner and that Western English, by being the "most correct" form of English, is better to learn creates friction in Chinese-written EFL pedagogy. It is a challenge to the power of tradition in Confucian culture (Tang \& Absalom, 1998, p. 119). Adoption of Western methods is, at best, mixed.

Much of China's traditional EFL pedagogy is, from the Western view, outdated and less effective (Tang \& Absalom, 1998, p. 118), based on models from the Grammar Translation Approach which focuses on memorization, grammatical rules, and sentence translation. This teaching model fits well into the Confucian traditions of teaching in China, which is teacher focused (Tang \& Absalom, 1998, p. 121; Lianjun, 2008). However, under this system many students find themselves unable to effectively communicate outside the classroom, a phenomenon which is known among Western businesses and EFL professionals as, "deaf and dumb English,” or, "high score, low ability" (Lianjun, 2008). The Communicative Approach favored by Western educators is either viewed as dubious by many Chinese educators (Tang \& Absalom, 1998, p. 123; Yang, 2010, p. 161), despite a better track record for generating capable speakers, or applied unevenly:

[China is] a huge, rapidly developing country with an enormous population of over 1.2 billion. There are significant differences in language teaching developments between the 
major cities and... the countryside, between coastal and inland areas, between north and south, between key and non-key schools and universities. There is wide variation in teaching quality. At the same time, there are clear centralising tendencies of national syllabuses and exams, widely used textbooks, and clear perceptions of common practice among teachers. While recent economic development in China has been remarkable and there is much evidence of social change, the perceptions and expectations in the education system have been relatively slow to change. This is particularly reflected in the beliefs of teachers, students and their parents about how teaching and learning should be carried out and what they expect students to achieve in their education. (Cortazzi \& Jin, 1996, p. 61)

More contemporary work notes that the process of change is becoming more common, if only because of the addition of new technologies and internet-based tools (Tianjin, 2008). There is also a burgeoning private education system in China, from preschools to, "cram schools," designed around China's all-important entrance exams. I can additionally count my personal experience in adult education in Chengdu in 2017.

Culture plays a significant role in whether using traditional learning styles that the students are used to, or attempting to teach them a new learning style they are not comfortable with while also teaching them English, will result in better language retention (Tang \& Absalom, 1998, p. 127). In the case of China, various pressures lead both the students and the educators to favor traditional styles. Although Western pedagogies focus on student capabilities, they were not universally intended to account for the Confucian cultural constructs which render them nontraditional and unfamiliar to students in Chinese contexts (Tang \& Absalom, 1998, p.121). 
For example, a dominant trend in EFL teaching is creating a pure, "target language," environment, which is to say that the educator should only speak English. However, some studies out of China suggest that using the primary language (L1) in EFL classrooms to teach a second language (L2) can aid the student in retaining more of L2 (Liu, 2010, p. 10; Tsui, 2010, p. 198; Zhenhui, 1996, p. 469).

Significant challenges remain in the way of adopting more Western pedagogy for China. Classroom size is usually over 50 students, the national testing standards take the focus of language education from the actual acquisition of language, the teachers are rarely native speakers or even competently fluent, and the students find it difficult to break from known learning styles (Zhenhui, 1996, p. 467; Tang \& Absalom, 1998, p. 124; Lianjun, 2008; Bai \& Hudson, 2010, p. 392; Yang, 2010, p. 161). On the Western side, there is an attitude of Western superiority which can be characterized as foreigners coming to save the backward Chinese pedagogy, with all the friction such an attitude brings (Tang \& Absalom, 1998, p. 118). There is also a severe misunderstanding of the power of tradition in Confucian contexts (Tang \& Absalom, 1998, p. 118; Govardhan, Nayar \& Sheory, 1999, p. 115).Attitudes on the part of a number of western educators that the backwardness of Chinese pedagogy needs "rectifying" does not necessarily reflect an understanding of local context and local needs.

Even in all of this, there is still movement towards adopting more of the Western approach (Tang \& Absalom, 1998, p. 124). There is specifically an educator-led movement to better adopt and understand the Communicative Approach in Chinese contexts (Zhenhui, 1996, p. 459; Yang, 2010, p. 159), though these authors agree there is little clear consensus on what strategy should be utilized going forward. Students frequently reject the methods used by the 
Communicative Approach (Zhenhui, 1996, p. 467; Tang \& Absalom, 1998, p. 118), and the Communicative Approach itself broadly seeks to garner student involvement beyond passive reception of material. Still, more and more Chinese educators demonstrate, a great transformation in pedagogical beliefs. Teachers are realizing that their role includes more than adhering to a teacher-centered class model. Methodology in classroom teaching is drawing teachers' attention. Classroom interaction is required for the assessment of teaching work. Instead of being mere knowledge receivers, students are encouraged to be active participants in classroom interaction, ready to present their ideas or argue for specific viewpoints (Lianjun, 2008).

Additionally, in the People's Republic of China (PRC) the government has dropped much of the ideological control from Chinese EFL education:"Instead, more pragmatic considerations development of cognitive skills and pedagogical appropriateness - have gained prominence" (Guangwei, 2002, p. 38). These changes, however, are not universally applied. Major cities remain the government's focus, and rural areas continue to not benefit from China's modernizing EFL education (Guangwei, 2002, p. 45). Finally there is a wide understanding that Chinese EFL academic research is lacking: "Not only is there a lack of renowned researchers (Wen 2003), but the average output of quality research by Chinese TEFL academics is also low... Compared with the large number of [Chinese] English learners, Chinese TEFL research has little influence in the international arena" (Bai \& Hudson, 2010, p. 392).

The current state of modern EFL education in Chinese cultures is a complex interaction between traditional Confucian values, globalization-driven modernization, the corporatization of education, uneven application of a centralized pedagogy, and a lingering transition from 
education as a method of instilling government-desired values. It is in this complex interplay that the clash between tradition-based Grammar Translation Approach pedagogy is challenged by the more modern and Western Communicative Approach pedagogy. This is the context in which any study of EFL idiom education in China must be understood, and further why attempting to trace continued friction between Eastern and Western approaches is so important.

\section{Defining Idiom}

This paper will highlight the importance of idiom education for the overall competence of EFL speakers because, "idiomatic expressions occur frequently in daily spoken and written communication. Pollie et al. (1977) found idiomatic expressions arose every 3 to 4 minutes in conversation" (Hua, 2017, p. 329). The study of idioms in EFL contexts hinges on two key concepts: idiom transparency and idiom frequency. Frequency is easily defined as how common a particular idiom is in its natural use. Transparency is the conceptualization of how easy an idiom is to analyze or comprehend without knowledge of its definition. For example, doing things, "by the book," is relatively transparent, because following rules implies a rulebook, and English learners can generally grasp the metaphorical meaning easily. On the opposite end, "kick the bucket," is relatively opaque because its meaning, "to die," is not easily analyzed from its actual words. In effect, frequency determines which idioms are most important to teach since they are the ones most frequently used, and transparency determines how difficult particular idioms can be to understand in isolation.

However, neither of these elements is central to defining an idiom. "Many linguists, instead of giving a narrow definition of idioms, prefer to describe a scale or continuum," from transparency to opacity to categorize idioms (Grant, 2004, p. 42). Various scholars have 
attempted to truly pare down to what an idiom is, to separate them from other metaphors and forms of figurative language. This paper is not designed to engage that discourse. Instead, for the purpose of narrowing down studies, it will rely on the commonly used criterion for defining idioms: non-compositionality: "In other words, the meaning of idioms cannot be predicted from the meaning of their constituent parts" (Grant, 2004, p. 40). Therefore, all idiomatic language which can (and frequently does) challenge Chinese learners with figurative and non-literal meanings is the focus of this paper.

A majority of the pieces reviewed refer to two articles on this topic in particular, a 1999 article by Thomas Cooper and a 2000 article by Frank Boers. Taken together, they represent an important summary and examination of the dominant trend in EFL idiom education: cognitive linguistics. Cognitive linguistics represents the fusion of the Communicative Approach in applied linguistics and a psychological approach to education. Adding a psychological portion to the education is important, because idiom education not only touches on linguistic forms, but also culture, language transference, and efficacy practices. Cooper and Boers create the starting point for understanding this cognitive linguistic discourse in EFL contexts.

According to Cooper (1999), very few studies on idiom comprehension prior to his article focused on L2 English speakers, finding two notable exceptions (p. 234). Due to this lack of material, Cooper tried to use L1 idiom comprehension models to direct his study in L2 comprehension. These reference models detail the strategies an L1 learner uses to comprehend new idioms. His final results describe the L1 models as ineffective when tracing the strategies an L2 learner uses, because 12 learners rely on a different set (p. 255). The new strategies Cooper found of particular note are: "guessing from the context to figure out the meaning of the 
expression (Strategy GC, leading to a correct answer 57\% of the time), using the literal meaning of the idiom (Strategy LM, 22\%), using background knowledge (Strategy BK, 12\%), [and] referring to an L1 idiom as a key to the meaning of the English idiom (Strategy L1, 8\%)" (p. 252). Cooper then forms pedagogical recommendations for teaching English idioms to L2 learners based on the effectiveness and frequency of the strategies the learners in his study employed (with caveats due to the limited number of students he had to sample). Many of the articles that form the core focus of this work directly reference these same recommendations. We further see the strategies these students used replicated among the Chinese students who are tested.

Boer's study, on the other hand, focuses on the background metaphorical meaning of idioms. He conducted a study which grouped idioms by thematic components, "(e.g. "Anger is a hot fluid in container," to group together, "anger welled up inside me," "flipped their lid," “simmer down!" etc.) (p. 555) as previously grouped by other scholars. Boers then compared students who received idioms presented as such versus a control group which was given the same list of idioms to memorize sans the metaphorical background. Boers theorized that L2 English learners, lacking the socio-literary frame of reference of L1 learners, would show improved scores over the control group if instructed in some of this framework (p. 553). His hypothesis was born out successfully in the 3 different experiments he conducted on a group of L2 English-learning middle schoolers residing in Belgium. Boers acknowledged the limitations of testing this hypothesis in a French classroom and suggested studies in primary languages more lexically distant from English than French (p. 563). In effect, Boers pioneered the use of 
metaphorical motivation when teaching idioms to L2 English learners. The suggestions he generated are carried forward and referenced by many of the following articles.

There is a third book, Metaphors We Live By, by Lakoff and Johnson (1980), which features prominently in the discussion of metaphorical roots of idioms in English. Almost every paper referenced in this examination refers to the book; however this paper will not as it is also analyzed by the Boers article and it would not contribute to a further understanding of the topic. It is a central work to the metaphorical study of idiom, but the necessary details for Chinese contexts can rely on Boers as this paper does.

Up until the 1990's, the primary comprehension strategy for idioms was rote memorization in both L1 and L2 contexts (Boers, 2000, p. 554; Shan-Fang, 2008, p. 129) as idioms were viewed as "arbitrary," and thus a student could not learn to understand an idiom at a deeper level. More recent work challenged this notion and demonstrated that many if not most idioms can be, "motivated," (Boers, 2000, p. 553) by metaphorical or etymological roots. This motivation grants a student the theoretical framework not just to understand a single idiom at a time but all the idioms which share a single motivation (e.g. "life is a journey") (Shan-Fang, .2007, p. 148). Non-compositionality is how we can define the problems idioms present to L2 learners. Metaphorical motivation provides the solution proposed in the dominant cognitive linguistics discourse.

\section{Methodology}


This paper's goal is to present a contemporaneous view of how idioms are studied in Chinese EFL contexts. This goal requires limiting the focus of papers to a specific time and to Chinese learners; this analysis focuses on papers written between 2004 and 2018. While this limitation does not exclude Western researchers over Chinese researchers, in practice it primarily limited the corpus to Chinese researchers Of the articles in the main corpus of this research, only two are from Western researchers (specifically: Kilroy \& Scalia, 2015; Yu Ren Dong, 2004)..

This abundance of Chinese researchers is rather surprising, as one of the largest sources of Chinese research, the China National Knowledge Infrastructure (CNKI) database, is effectively closed off to the West. Logging into the CNKI database is quite possible, as it only requires a profile on the popular Chinese social media network WeChat. However, the database is geographically tied to Chinese mainland Internet Protocol (IP) addresses. Thus while I can login to the database, attempting to retrieve any of the articles results in a denial. One other paper was similarly locked behind a database geographically locked to Poland, however the CNKI database simply by virtue of being geographically located in the region this work focuses on contains an immense wealth of literature relevant to the topic. If Chinese scholars with access to the CNKI database are interested in performing this study again just using that database to share their results with Western researchers, it would be beneficial to the discourse at large.

Because of that limitation, this review relied instead on several databases and resources to gather its work. These sources include Google scholar, JSTOR, the Portland State University library database, Ebscohost, Sciencedirect, Wiley Online Library, and any databases or articles linked via the ones already mentioned. The various primary topics presented through theoretical 
discussion and empirical research in these articles will be correlated and traced in their own detail.

Due to the specificity of the research, the challenge was not selecting research from a larger body of work, but finding articles in the first place. There is a large corpus on very similar material such as education strategies for phrasal verbs or collocations in Chinese EFL contexts. There is similarly a large body of work dissecting the translation strategies between English and Chinese idioms. Digging up the work specific to education of English idioms in Chinese EFL contexts involved working between those two large corpuses to find the relevant material. By following the above mentioned limitations, this article has 21 papers which can be broadly categorized into the following key topics.

\begin{tabular}{|l|l|l|}
\hline Category & Focus & Number of Papers \\
\hline $\begin{array}{l}\text { Comprehension and } \\
\text { Retention }\end{array}$ & Idiom motivation awareness raising & $8 *$ \\
\hline Motivating Factors & Metonymy and metaphor & 8 \\
\hline Familiarity & Unfamiliar idioms & 3 \\
\hline Student Perceptions & The experience under teaching methods & $3 *$ \\
\hline
\end{tabular}

*The article Ying-Ying 2013a is split between these two topics due to its relevance to both.

\section{Findings}

\section{Comprehension/Retention}

Several studies conducted in Chinese contexts focus on the how exactly students comprehend and retain idioms. Six of the following studies all selected a group of EFL students and tested their initial understanding of idioms, follow a method of education, and then retested the students to measure improvement (Hua 2017; Lei 2009; Shan-fang 2007; Shan-fang 2008; 
Ying-ying 2013a; Youmei 2011). These studies used a control group who only received idiom education via rote memorization and compared it to their hypothetical works. The two outliers tracked records of idiomatic usage and improvement over time, which is to say that they contrasted usage of students who had different lengths of English study, but did not test against different teaching methods (Xiaoli 2014; Kaisheng 2016). All these papers except one suggest that it is the understanding of metaphorical and etymological background that best aids EFL students in Chinese contexts, as opposed to the more traditional rote memorization. The outlier (Kaisheng 2016) found no difference between the two education strategies in reception testing, but did find a difference in production testing.

Common themes emerge into this section. Chinese cultural concepts of figurative meaning can bleed into a student's understanding of an idiom's figurative meaning, also called L1 transfer. Vocabulary size and correct usage of idioms are scrutinized as a factor in comprehension and retention. Educator importance is highlighted. Finally, scholars are exploring idiom comprehension and retention testing over educational periods, between levels of English education received, and whether or not contextual clues are provided.

Idiom motivation is cultural, which is to say that conceptual metaphors commonly used by a language are inextricably intertwined with a the culture they are born in (Cooper, 1999, p 258; Hua, 2017, p. 330; Xiaoli, 2014, p. 935). Different cultures create different figurative imagery. For instance, English has long held that knowledge comes from the brain, but ancient Chinese concepts of knowledge see it centered in one's belly. When L1 and L2 cultural imagery disagree, students have a harder time comprehending the L2 concept utilized (Xiaoli, 2014, p. 940), from which we extrapolate that students utilize familiar L1 cultural concepts when 
engaging with new L2 material. This is called L1 transference, and is an especially important consideration in idiom pedagogy, as L1 transference with figurative language may not merely drive the student to use familiar linguistic concepts but to actually form incorrect understandings of the figurative meaning based on the understanding formed in their native culture (Kaisheng, 2015, p. 19; Xiaoli, 2014, p. 940).

The culturally bound nature of idioms limits the ability of students to immediately comprehend an idiom (Ying-Ying, 2013a, p. 73). The binding does not completely prevent any understanding, and there is positive correlation between general vocabulary size and idiom comprehension (Ying-Ying, 2013a, p. 59). However, current Chinese EFL teaching methods are not meaningfully addressing the correct usage of idioms. Rote memorization techniques can certainly add more idioms to a student's lexicon, but accurate usage doesn't necessarily follow:

The results show students have achieved quantitative gain but failed to make significant progress in accurate bundle use during their four years of English learning. It turns out to be noteworthy that quality speaks louder than quantity in benchmarking phraseological proficiency. More does not necessarily mean better." (Kaisheng, 2015, p. 21).

Not only this, but some of the most popular lexical bundles can be the ones least accurately used by Chinese EFL students (Kaisheng, 2015, p. 20). This does not improve during the education process; advanced learners in Chinese contexts do not use idioms with a higher accuracy rate than intermediate students even though they may know a higher total number (Kaisheng, 2015, p. 19; Xiaoli, 2014, p. 940). 
What does show consistent improvement over the memorization method is adding metaphorical background to the lesson plan (Boers, 2000, p. 569; Hua, 2017, p. 335; Shan-Fang, 2007, p. 157). This improvement is demonstrated during post-lesson comprehension testing (Shan-fang, 2007, p. 157) and student retention testing a month afterwards (Shan-fang, 2008, p. 138):

Raising the learners' awareness of metaphors consciously in the process of language teaching... provide[s] strong evidence for the position taken by Boers (2000) that metaphor awareness has a positive influence on vocabulary learning in English as a foreign language context. (Shan-Fang, 2007, p. 159)

Comprehension is further aided by the presence of context clues (Cooper, 1999, p. 248; Hua, 2017, p. 335). EFL students in Chinese contexts can have a harder time discerning the meaning of idioms in isolation, as finding the figurative meaning without metaphor and etymological training reduced tested students down to direct translation (Hua, 2017, p. 333), and a handful of guessing strategies which may or may not yield the correct translation (Cooper, 2000, p. 252).

This generally holds true when the idioms are divided into subtypes such as metaphor and proverb (Youmei, 2011, p.360); however these results are not as conclusive without the presence of an instructor (Lei, 2009, p. 61). Thus while the student's success is the primary metric by which to measure progress, instructor competence is an important factor in setting students up for success. We can see this in action in the one article which, counter to the general trend, found no statistical distinction between the performance of the rote memorization control group and the etymologically educated experimental group (Lei, 2009, p. 51). The focus of this study was the 
usefulness of online resources, and as the students themselves mentioned in the follow up survey,

“the lack of teachers' assistance and guidance is one major drawback of online learning" (p. 61). Student success in idiom understanding may be predicated on not just the methods of metaphor awareness raising but on the ability of educators to adapt the material to their classrooms and the needs of their students for figurative language education.

There are some important gaps in the literature on idiom comprehension and retention in Chinese contexts. There is no consistent answer concerning the best application of metaphorical or etymological education. Some suggest dedicating a class, some suggest adding it into the established pedagogy. None of these studies were long-term longitudinal studies which tracked their students after the experimental metaphoric education ended. Finally, all of these studies concerned students in secondary or post-secondary education. There is no data on whether introducing transparent and potentially easy to comprehend idioms earlier in a Chinese student's education will help their overall understanding of them, or really what can or should be done about the lack of idiom and figurative meaning in Chinese pre-college EFL classes at all.

\section{Motivating Factors: Metaphor and Metonymy}

Idioms can be motivated by several different figurative forms. These studies highlight the difficulty in understanding idioms by focusing on a particular type of motivation such as metaphor or metonymy. These motivation processes are particularly apparent in idioms with low transparency. To define, metaphoric motivation sees something as directly equivalent to another concept, such as, "anger is fire," in idioms such as describing someone as smouldering. Metonymy by contrast is a substitutive or, "stand-in," process where one object replaces another, 
such as discussing, "the crown," to discuss the Queen of England. There are more forms of motivating idioms than these two, however only these two have studies dedicated to them on the topic of English idioms taught as EFL in China.

The goal then is to correlate an understanding of culturally bound metaphorical meanings with improved idiom retention in the student. (Yi-chen \& Huei-ling, 2013, p. 13). This follows from other research which argues that purposely invoking a student's L1 metaphorical knowledge of their native language can deliberately utilize L1 transfer, "through comparison and contrast to help them transfer knowledge into English.” (Yu, 2004, p. 31). It is inherently a process of relating metaphorical knowledge between L1 and L2.

Two articles compare motivating factors, including metaphor and metonymy. They attempt to identify which forms of idiom motivation are the hardest and easier forms for students to understand and retain. These studies which analyze idiom comprehension by type did not perforce approach the question identitically. One study looked to compare comprehension rates against a control group (Wangmeng, 2017, p. 24) to determine if particular forms of idiom motivation did not benefit from motivation awareness raising. The other study divided students via pretest into high-scoring and low-scoring groups (Fushou, 2016, p. 807) to answer the question of how overall English competence correlates to figurative English competency with different motivating factors. These studies lay out which forms of idiom motivation are hardest or easiest for students in Chinese contexts to comprehend.

In both studies, the motivating factor students understood the easiest and retained the longest after instruction was metonymy (Fushou, 2016, p. 809; Wangmeng, 2017, p. 30). The motivating factor students performed the worst in was with metaphors (Fushou, 2016, p. 809; 
Wangmeng, 2017, p. 30), to the point that overall English competence had no statistical bearing on the comprehension rates for metaphors. (Fushou, 2016, p. 809).

Given the student difficulty and the centrality of metaphor to idiom motivation, it should not be surprising that four articles examine idiom education purely about metaphorically motivated idioms. One is purely theoretical, discussing the interrelation between idiom and metaphor in EFL contexts. The next is similar, but includes examples of this process occuring in situ via the researcher's own student educators. The final two articles are both case studies, where educators tested their theories in the classes they teach.

The sole theoretical article compares English and Chinese idioms which share similar motivation under the framework laid out by Lakoff and Johnson. This comparison between Chinese and English sets up a discussion of EFL idiom and metaphor education. "Teachers should make it clear to students how a series of idioms are related to their conceptual metaphor motivation... [and] to encourage students to deduce the metaphorical meaning of idioms" (Xiuzhi, 2010, p. 208). By first demonstrating familiar Chinese metaphors which all carry a similar motivation, the teacher can lead the students into seeing English metaphors which use the same motivation. Further groups of motivated metaphors could them be presented without their motivator, granting the students the opportunity to puzzle out the motivation common between them.

Further yields from this theoretical discussion touch on the commonalities of the four metaphor articles, and in certain respects to the general goal of comprehension and retention. Common factors among these papers include raising metaphor awareness of the students, a direct link from the Boers article. Further, they suggest exploring cultural contexts of the metaphors. 
Finally, the research suggests improving the competence of the educators themselves, and one additional study of educator classroom behavior specifically examines the teacher's use of metaphor.

Given its centrality to Boers' work, it is understandable that studies which focus on the relationship between idiom and metaphor should follow closely in his wake. His work was designed to, "corroborate the thesis that an enhanced metaphor awareness on the part of the language learner can facilitate his or her retention of novel figurative expressions" (Boers, 2000, p. 569). It is further corroborated in these studies, thought not all in the same manner. Multiple educators give the sense that students view metaphors as part of a purely literary practice (Xiuzhi, 2010, p. 208; Yu, 2004, p.29), and as such are only accustomed to seeking out the literal meanings of the words in front of them :

Our students, for example, ... go through class with dictionaries open and mark up texts with a myriad of Chinese words that approximate the translation. First, this indicates that the students are focused on literal meaning rather than subtext, as the surface meaning of the texts often still eludes them. Second, it suggests that any complexity in the text also eludes them. (Kilroy \& Scalia, 2015, p. 2)

The strategies for raising metaphor awareness cover a wide range. Perhaps the most creatively engaging among this research is the use of poetry which, "might be used as a vehicle to better understand metaphor and, as a result, context" (Kilroy \& Scalia, 2015, p. 2) The students are asked to study and analyze poetry, and then generate metaphors on their own within specific tasks to demonstrate an ability to think beyond literal meanings. (p. 6). These tasks were designed to, "gauge the short-term efficacy of using poetry to strengthen students' relationship 
with metaphorical and idiomatic language" (Kilroy \& Scalia, 2015, p. 5). Along the same lines, another paper had students in a writing course study idiom laden articles in between drafts of a paper to track student idiom usage and short-term improvement of metaphor awareness (Yi-Chen \& Huei-Ling, 2013, p. 17). While both of these studies demonstrate an increased usage of metaphor and idiomatic expression, there is no follow-up comprehension testing, and none of the examples of student writing cited by these studies demonstrate native English idiom accuracy. The authors' assertion that encouraging students to develop new metaphors will improve their ability to learn existing ones also requires the authors to disregard student efficacy in their own conclusion (Kilroy \& Scalia, 2015, p. 10). It would be helpful if the studies engaged in longer-term testing to see if short-term metaphor awareness raising via creative outlets actually yields long-term comprehension skills.

Part of this lack of idiom comprehension can be explained by the cultural binding of idioms, as, "even imaginative or poetic metaphors are governed by cultural conventions and our beliefs and values" (Yu, 2004, p. 30). Thus the metaphors created by these students are probably related to Chinese culture, further highlighting the need for not only raising metaphor awareness but cultural awareness as well. One can potentially raise cultural awareness by deliberately utilizing the cognitive process of L1 transfer for a, "contrastive analysis" (Yu, 2004, p. 31): Research... in second-language acquisition has suggested the benefit of activating adolescents' metaphorical knowledge in their native language through comparison and contrast to help them transfer knowledge into English... This can raise students' general language awareness and crystallize key issues related to language, thought, and culture in both languages. (Yu, 2004, p. 31). 
Thus it behooves an educator to engage with cultural material which motivates the target L2 metaphors (Xiuzhi, 2010, p. 209). This engagement perforce requires teachers who are themselves educated on the metaphorical background of the material: "Awareness of conceptual metaphors does not guarantee L2 learners' automatic access to conceptual metaphors," (Yi-Chen \& Huei-Ling, 2013, p. 18). Thus the educators must be capable of leading students through the cultural and etymological roots of the metaphor or idioms in question. Again, most of the Chinese EFL educators are not native speakers themselves, which is a, "severe challenge for... Chinese teachers. Therefore, schools should make every effort to provide opportunities for teachers to further their study of metaphor theory" (Xiuzhi, 2010, p. 208).

Teachers who can successfully lead their students in this way can contribute to student efficacy, as detailed by Yu (2004):

Because she cultivated an environment for learning about cross-cultural metaphors, her second-language learners no longer feared metaphors or felt inferior about their language skills. They also felt that they had something important to share with the class. (p. 31). The importance of educator competence can not be understated. The, "metaphorical features of teachers' directives are... the facilitator in providing more comprehensible input for L2 learners in college EFL classroom context ... and motivat[e] the knowledge background of L2 learners" (Lu \& Wang, 2014, p. 273). Lu \& Wang go on to further argue that the classroom contexts and the educator's use of metaphor are mutually reinforcing. When the educators used metaphor in their classroom directions, the students started responding with similar figurative language (p.274), and thus Lu and Wang concluded, "the findings of this study show that the students' metaphoric competence need to be consciously cultivated in college EFL classrooms 
and the important role of teachers' directives with metaphorical features should not be ignored" (Lu \& Wang, 2014, p. 274).

All of the factors described previously in this section are reinforced by a unique study which examined idiom variants, where students were taught the primary idiom (e.g. "Spill the beans," or, "off the hook,") and then tested for understanding of variations of the idiom ("Spill a single bean," or, "removing the government from the economic and political hook") (Guo, 2014, p. 436). The study found that overall English competency was a huge factor in how students interpreted idioms, which strategies they prefered, but not in accuracy rates (Guo, 2014, p. 442). The article concludes:

The results of the study also set off alarm bells in current L2 idiom pedagogy ....college level Chinese EFL learners not only found it difficult but also performed unsatisfactorily in their comprehension of novel English idiomatic expressions [sic]. This problem in L2 idiom teaching and learning rigorously questions the effectiveness of ... rote-memorization for idiom acquisition (Guo, 2014, p. 443).

Guo moved on to trace the habitual responses of Chinese educators and students in the classroom. Teachers felt like it was impossible to educate students who hadn't already memorized the idioms, but due to the reliance on rote memorization they did not have additional methods to choose from. This caused students to give up, or to utilize the comprehension strategies identified by Cooper with low success rates (2014, pp. 443-444). "It seems that the dominant rote memorization runs the risk of depriving L2 learners of the opportunity to cultivate their analytical and inferential abilities in language learning" (Guo, 2014, p. 444). From this study we can glean that the tradition of rote-memorization, without other techniques to support it, 
can depress student effectiveness, and further can limit the capabilities of the educator as they do not have the tools they need to lead students through the complexities of figurative language. Thus these papers are primarily following directly from Western pedagogy rather than demonstrating friction against it.

These studies of motivating factors for idioms in EFL contexts end up covering significant topics in EFL pedagogy. Studies which differentiate idioms find metonymy the easiest motivating factor for Chinese students and metaphors the hardest. This feeds directly into Boer's work on metaphor awareness. The researchers who follow directly behind Boers, much like the researchers investigating comprehension and retention, highlight the importance of culture in teaching strategies. They further discuss the role of the educator, and of the need to ensure these educators are themselves capable in tracing figurative meaning.

Two of these papers actually do demonstrate friction against the loss of the, "traditional methods." (Xiuzhi, 2010, p. 209). Both of these papers still accept and recommend the usage of Western methods but, "the traditional method should not be abandoned completely," (Yi-Chen \& Huei-Ling, 2013, p. 18). This single phrase does not seem like categorical resistance to Western pedagogy, but does also seem to indicate a hesitancy to completely embrace it. It is also not consistent resistance within this key topic, as the other two papers explicitly and solely engage with the Western discourse.

There are still questions that this section raises, areas where further research can progress. It seems widely accepted by these researchers (and indeed, Boers as well) that certain idioms do not translate as well into a conceptual metaphor theory. But these problem areas are not defined. That is to say, none of these papers demonstrate where English metaphor and Chinese metaphor 
diverge significantly. Nor is there work to discover exactly why metonymy is easier for Chinese students to understand, or any mention of Chinese examples of metonymy at all. Second, there is no study covering accurate use of these idioms as seen in the subsection on comprehension and retention. This is particularly poignant in the study of comprehending metaphor, as some of the studies show students creatively engaging with English metaphor in a way that requires the researcher to discard efficacy. Finally, there is only one study in this section which included a control group, but it was only clarifying the performance differences based on the motivating factors. None of these studies with solutions actually examined if their proposed improvements were better than the previous education strategies or rote memorization. There is a lot of room to explore comprehension of metaphor on all levels in Chinese contexts.

\section{Familiarity}

Three studies focus on the impact of idiom familiarity on idiom comprehension, as a form of understanding how students treat idioms they are familiar with and unfamiliar with differently. Familiarity here is very similar to idiom frequency, except instead of frequency of production in native use its frequency of idiom exposure to the learner. Two of these studies explicitly test against familiarity in their subjects, while one encounters the factor as a byproduct of their comprehension and translation study which effectively ends up answering two of the paper's research questions.

Defining idiom familiarity for the purpose of study is not a universal process in these articles. One paper directly asked the subjects to rank their familiarity with the idioms in a pretest (Ying-Ying, 2013b, p. 49), with the purpose of only testing against the idioms reported as 
"unfamiliar" to the students. The other test used 100 students who had passed Taiwan's College English Test Band 4 to rank the target idioms' familiarity in general (Shen, Wang, Liu, 2017, p. 78), then used this familiarity ranking to divide idioms into familiar and unfamiliar categories for the actual test. Said test used subjects who had passed the College English Test Band 8, the highest test Taiwan has in their collegiate system and thus intentionally test subjects with the highest competency still in a college career

These three studies do not test for the same data, and comprehension is not a dominant driving factor. In fact, only one study looked to understand idiom comprehension via translation accuracy (Lu, 2016, p. 869). The other two studies examined accuracy rates for unfamiliar idioms (Ying-Ying, 2013b, p. 52), and response time as well as accuracy rates when encountering an idiom, with a division of familiar and unfamiliar idioms to compare the two categories (Shen, et. al., 2017, p. 81). Taken together, they have several common themes from the results of their studies. Chinese student accuracy rates for unfamiliar idioms is very low. Further, idioms that are familiar still have a notable inaccuracy rate, indicating that the education process doesn't completely satisfy the needs of the students. Finally, the culture and the L1 of the student heavily inform their ability to comprehend new idioms in the L2.

Chinese students encountering unfamiliar idioms are not well equipped to accurately process the meaning from the phrase. A selection of college sophomores at a Taiwanese university had an accuracy rate of just under half with unfamiliar idioms (Ying-Ying, 2013b, p. 55). However, learners who had passed the highest level English proficiency test in the country only managed an accuracy rate of $65 \%$ (Shen, et. al., 2017, p. 81). Learners at any level do not have the tools needed to adequately parse out idioms with high rates of accuracy. This high rate 
of misunderstanding is doubly confirmed when students are tasked with translating the idioms into Chinese (Lu, 2016, p. 875).

This is compounded by students forming incorrect understandings of the idioms that are familiar to them. Those same high-achieving students who achieved an accuracy rate of $65 \%$ for unfamiliar idioms only managed an accuracy rate of 71\% for familiar idioms (Shen, et. al., 2017, p. 81). Similarly, the Taiwanese sophomores who self-reported which idioms they are familiar with had an accuracy rate of only 75\% (Ying-Ying, 2013b, p. 54). Thus we can say that students of English are forming an incorrect understanding of English idioms even when they otherwise believe they know the idioms in question. Familiarity was a huge factor in how fast students responded to idioms in the electronic test (Shen, et al., 2017, p. 81), thus an L2 learner will spend less time comprehending an idiom they believe they are familiar with but there is not a huge increase in accuracy rate.

The same holds true for idioms which are similar to Chinese idioms in concept. This, "means that an increased degree of L1-L2 similarity between the English idiom and its Chinese translation equivalent foreshadows easier comprehension and interpretation" (Ying-Ying, 2013b, p. 61). Students also more reliably translate idioms correctly when there is a clear similarity to a Chinese equivalent (Lu, 2016, p. 877). This reinforces the understanding that, "second language learners may rely on the literal meanings and the conceptual systems in the first language to process figurative language in second language comprehension” (Shen, et. al., 2017, p. 76).

Determining the relative similarity to Chinese phrases of several idioms is, in the case of these researchers, generally only done after the study is concluded. However, one study attempted to categorize similarity to Chinese idioms in a four-part scheme. This was idioms with 
equivalent translations, idioms with partially equivalent translations, idioms with no equivalent translation, and finally, "false-friend," idioms or, "English idioms which cannot be translated literally into Chinese, yet whose literal translation makes sense in Chinese and denotes a different meaning other than the target idiom's meaning" (Ying-Ying, 2013b, p. 50). It is notable that when subdivided in this manner, students performed worst with idioms which had no equivalent translation and false-friend idioms (Ying-Ying, 2013b, p. 59).This confirms that Chinese students more easily understand idioms that are similar to their L1 by actually categorizing the idioms in such groupings rather than discussing the factor after the study is concluded.

To conclude this section, idiom familiarity is shown to have a large impact on the comprehension of idioms for Chinese learners; however said familiarity is not in and of itself enough to satisfy the needs of of the students. Clearly, the study of idiom familiarity on Chinese idiom comprehension also follows directly from the work done by Cooper and Boers, and there is no miscommunication between Western and Chinese researchers visible. Instead, these researchers are furthering the work of the two scholars by examining idiom familiarity in detail.

So where can the research presented here be push further forward? The first place to look is probably in the conceptualization of idioms in the first place. Is it possible that the idioms most familiar to a native Chinese speaker are not the most frequent idioms in English usage? It would be worthwhile to explore this area of inquiry. Next, while one study did attempt to classify the target idioms by factors of translatability, said ability is not a direct approximation for opacity. Idioms could have direct translations into Chinese while still being opaque. Finally, given that 
familiarity is frequency of exposure to the student, it would be useful to study learners before they are in the college level. None of these studies discuss students before their college careers.

\section{Student Perceptions}

A trio of studies seek to understand how Chinese students perceive English idioms and the education thereof. These researchers asked students specific questions to try and understand their needs or expectations, in order ensure the students are getting the most out of their education, with the pedagogical theory driving their education. Two of the studies qualify their data by comparing it to student performance, trying to find what higher performing and lower performing students view differently. One study analyzes how students view any given idiom and its relative transparency before and after metaphor awareness education. These studies also include the only paper which extensively defends rote-memorization.

Two of the papers are interested not only in the subjective opinion of the students, but the skill level of the students as well. Both of the studies ran tests to determine their students' vocabulary size in order to understand, "how learners' vocabulary size impacts their idiom comprehension," as a way of leading up to, "what their comprehending difficulties and general learning attitudes are toward idioms." (Ying-Ying, 2013a, p. 59). This paper mostly left the vocabulary skill data outside of the student opinions. The other study tested vocabulary, "not to see the subjects' language proficiency, but to divide the subjects into three groups by their scores---"high achievers", "borderline" and "low achievers" and then use chi-square analysis to see if there was a significant association between the variables: beliefs and scores" (Xiuping, 2011, p. 216). 
Xiuping's division by student performance is a key part of his defense of the Chinese style of rote memorization. However, his central thrust into the discourse is that the East and West don't conceptualize rote-memorization in the same manner:

The existence of opposing views on Chinese EFL learners' use of RL [rote learning] grows out of cross-cultural differences in belief.... thought has to be given to differences between CHCs [Confucian Heritage Cultures] and Western understandings of what RL actually is. It is worth making a distinction although it is difficult to find out the differences between culture-specific and more universal learning dispositions towards RL... What is important for this study is to explain the definition of RL through looking at explicit cultural beliefs. In this study, the literature research traced the origin of RL of Chinese learners back to the traditional CHCs beliefs about learning methods. It suggests that Chinese EFL learners favour RL, generally because they believe that their use of RL is a combination of repetition, memorisation, practice including reviewing which are leading to deep understanding rather than simple repetition/ memorization which are [sic] shallow and ineffective. (2011, pp. 12-13).

He then argues that other research has attempted to model how different languages can generate different mental systems for word storage, and, "it is possible that learners will continue to use these strategies for handling English words," rather than relying on the techniques used by native English speakers (Xiuping, 2013, p. 87). This is particularly important to his argument for student perspectives of idiom rote memorization, since they are, "impossible to guess, as they rely on tradition of usage rather than on common sense. For example, learners may feel they can 
only learn by memorisation that "cool as a cucumber" is "correct", while "cool as a carrot" is not." (p.86).

It for these reasons and others that Xiuping finds wide support for rote learning in his survey (p.239), with larger support from the high achievers than the low achievers (p. 225). If one is to question why rote learning sees such broad support, it is worth mentioning that multiple articles have pointed to the all-importance of entrance exams in Chinese contexts (Chen, Warden, Huo-Tsan, 2005, p.665; Lianjun, 2008; Xiping, 2013, p. 283), and, "the exam emphasis naturally leads to a reliance on memorization" (Chen, Warden, Huo-Tsan, 2005, p.665). The prefered learning style is as much a product of the discourse as it is the systemic needs of the students.

That being said, there does seem to be a student understanding of their need for idiom and metaphor education (Ying-Ying, 2013a, p.71). There is less agreement as to when in the education career to start educating (Ying-YIng, 2013a, p. 72), or under what methods, such as rote memorization or a model from the communicative approach and cognitive linguistics. This question ends up in central prominence even in something less directly related, such the study of student idiom transparency assumptions.

Transparency assumptions first interact with the non-compositionality of idioms. However the fact that this is a study of assumptions changes the focus from the idiom to the student, as the transparency, "does not come from the idiom itself but is related to the perceptions of the language user (Fernando, 1997). Thus, although idioms are composite units... learners' general cognitive skills have to be the deciding factor," (Jia-yi, 2015, p. 68) in whether an idiom is opaque or transparent. Since student cognition is the main deciding factor in idiom 
transparency, the results of the study, "indicate that when the concept an idiom represents is not very complex, providing L1 translation of the idiom would not necessarily help learners to connect the literal and figurative meanings of the idiom" (Jia-yi, 2015, p.65). Instead, while the study did not in and of itself conclusively understand the process students used to make assumptions (Jia-yi, 2015, p. 68), it did reaffirm the metaphor awareness raising argument made by Boers that students will benefit from metaphor awareness raising (a fact made all the more interesting by this study being one of the few papers that did not utilize Boers as a source).

The studies of student perceptions are less cohesive than some of the other topics this paper has traced. None of them trace these assumptions in the same manner, for the same purpose, or to similar ends. One specifically traced student assumptions in support of rote memorization, another just to understand the cognitive processes behind how students understand idiom transparency, and the final one looked to understand how students view idiom education in general. It should be noted that Xiuping's defense of rote memorization was a doctoral dissertation of which idiom memorization was but a small part. Further, neither Xiuping's study nor Jia-yi's study used either the Boers or Cooper articles as sources, making this topic the only one in this paper where they are not almost omnipresent in the background. This could be a factor into why these studies are less related than the other subsections, as they are not rooted in the same discourse in the first place.

That creates some larger gaps in the topic than the other sections demonstrate. Two of the studies divided students in to high-performing and low-performing groups. However none of them attempt to analyze why the low performing students aren't succeeding. It could very be that low-performing students are simply being failed by the system. Where is the line between 
student performance and systemic failure? Second, none of the studies discuss student perception of metaphor awareness, idiom retention, idiom familiarity, and other key concepts the study of EFL idiom largely hinges on. Part of this can be explained by the studies being about student perception, which is to say it is unlikely the students would universally be familiar with the pedagogy their professors rely on. However the lack of key concepts in this topic is perhaps its biggest weakness.

\section{Discussion}

At this point, each key topic has been traced relatively independently of the others, with no overarching summarization of the common factors. This discussion thus will examine the themes common among the topics and revisit the central research question: Where is the friction in the discourse between the East and the West, and how does it impact idiom EFL education in Chinese contexts? The express purpose of this discussion is not to trace the key topics but to analyze the Chinese EFL idiom corpus as presented in this paper as a whole to demonstrate what the dominant topics are. In particular, this discussion will highlight the impact of culture, L1 transference, retention, and educator competence in the corpus. Finally, this paper will highlight correlations between this corpus and the background analysis of the general state of the EFL discourse in China.

The corpus finds idiom education is inherently cultural. Students utilize their L1 when searching for images and figurative language analyses when encountering idioms in L2. This L1 transference highlights the psychological impact a student's primary culture exerts over their processing of language, and directly impacts their ability to correctly understand unfamiliar 
idioms. Thus while raising awareness for metaphors is paramount, special attention must be paid to idioms which are either completely unrelated to their primary culture or "false friend" idioms. Such idioms seem to directly relate figurative language in a student's L1 culture but are unrelated, and this misattribution will cause a student to form incorrect associations between the figurative motivation between their L1 and L2..

Teaching that kind of discernment requires capable educators. These studies demonstrate that educators who can lead students to understand the metaphorical roots of idioms will improve both the overall language competence of their students and the ability for students to parse figurative language. Such metaphor-raising also improves student retention of the targeted idioms. All of these factors were not as significant in the one study which focused on internet tools for teaching idioms, further highlighting the importance of the educator in this process.

But the fact that these studies all approach the topic of educators as not competent with figurative language can probably be read as a tacit support for Yang's point from the background section that many Chinese educators of English are not native speakers and do not have a good grasp of the language themselves (2010, p. 61). We can garner unintentional support for the conclusions of two background articles which were not included in this corpus. First, many of the students in the studies with a comprehension element fare very poorly during the pretest. This supports Lianjun's point that the current academic system is not satisfying the real world needs of the students, creating a situation called, "deaf and dumb English" (Lianjun, 2008). Given the incredible frequency of idiomatic expression in native usage, the systematic lack of figurative language education absolutely contributes to the problem. Second, this study targeted articles from 2004 to 2018, yet could only gather 21 pieces, roughly an article and a half per year for the 
whole of the greater Chinese region. This lack of accessible literature contributes to Bai and Hudson's article that education research is not highly prized in Chinese academia, and much of this data will not be accessed or used by the majority of Chinese educators (Bai \& Hudson, 2011, p. 405). This lack of research and distribution thereof heavily impacts the ability for the Chinese education to change and better meet the needs of its students.

Given these problems, where is the friction in discourse between the East and the West? One would've expected to see more resistance against Western methodology from the Chinese researchers based on the general state of the EFL discourse in China. Surprisingly, the overwhelming reality for these articles is: they directly trace their lineage to the Cooper and Boers article which are central to discussion of idiom education in EFL contexts. Only three articles pushed back against Western methods, and arguably two of them do not represent substantial resistance. The only paper whose resistance to Western methodology was central to its thesis was a paper examining the subjective opinion of students regarding rote memorization. To reiterate, the only notable example of friction to Western methods is from the students. This first supports Cortazzi and Jin's point that the perception of educators, students, and their parents which are slow to change in the face of globalization. The fact that this singular point of friction is based on opinion about rote memorization reinforces the fact that the friction is inherently a factor of culture and tradition.

Many of the papers reviewed here clearly already believe that the Cognitive Linguistics Approach is more effective than the traditional methods. Greater efforts to understand the Chinese cultural perspective could very well influence more researchers to this point of view, as the delivery of Western pedagogy does not need to be characterized as Westerners saving China 
from itself. There is no reason Western pedagogy needs to alienate Chinese educators, and such alienation will limit the success of the Chinese education system and the students therein.

\section{Conclusion}

If the friction in the East vs West discourse is so prevalent in the general corpus of EFL education, yet not as present in this corpus about idiom education, there must be an explanation for why this is the case. Exploring such a question speaks to the limitation of this research. The author of this paper speaks and reads Mandarin Chinese, however not on an academic level (only at HSK 4). Therefore the Chinese scholars selected all wrote in English, and it is possible this method of research selected a corpus already more predisposed towards Western thought. Further, the CNKI database was never accessed, and there could be more friction against Western pedagogy in that material. Finally the scholars Lianjun, Tang and Absalom, and Guangwei all suggested that the pushback against Western pedagogy by Chinese educators is slowly diminishing. The lack of friction in these more recent papers could be part of that process. However this paper does not have the tools needed to answer these questions, thereby limiting the scope of its research.

Despite these limitations, it is hoped that this snapshot of the discourse regarding idiom EFL education in Chinese contexts provides a stepping stone for future research. Further inquiries in the four areas of exploration this paper traces will now have a summary of the research after Cooper and Boer's seminal articles at the turn of the century. There are also always new potential ways to focus research beyond the four key topics, and further research can now more accurately identify the gaps going forward. As much as this paper spent its time examining the recent past discourse, it is future research which will most benefit from the work. 


\section{References}

- Bai, L., \& Hudson, P. (2010). Understanding Chinese TEFL academic's capacity for research. Journal of Further \& Higher Education, 35(3), 391-407. Retrieved from: https://doi.org/10.1080/0309877X.2011.569014

- Boers, F. (2000) Metaphor awareness and vocabulary retention. Applied Linguistics, 21(4), 553-571. Retrieved from:

http://sla.sjtu.edu.cn/thesis/Metaphor\%20awareness\%20and\%20vocabulary\%20retention. pdf

- Chen, J.F., Warden, C.A., and Huo-Tsan C. (Dec, 2005). Motivators that do not motivate: The case of Chinese EFL learners and the influence of culture on motivation. TESOL Quarterly, 39(4), 609-633. Accessed Oct. 26 2018, from: https://www.jstor.org/stable/3588524

- Cooper, T. (1999). Processing of idioms by L2 learners of English. TESOL Quarterly, 33 (2). 233-262 Retrieved from: https://onlinelibrary.wiley.com/doi/abs/10.2307/3587719

- Cortazzi, M. \& Jin, L. (1996). English teaching and learning in China. Language Teaching, 29(2), 61-80.

- Fushou, X. (2016). An empirical study of figurative competence of Chinese EFL learners. American Journal of Educational Research, 4(11), 806-810 Doi:

10.12691/education-4-11-5

- Govardhan, A., Nayar, B., \& Sheorey, R. (1999). Do U.S. MATESOL programs prepare students to teach abroad? TESOL Quarterly, 33(1), 114-125. Doi: 10.2307/3588194

- Grant, L. and Bauer, L. (2004). Criteria for re-defining idioms: Are we barking up the wrong tree? Applied Linguistics, 25(1), 38-61. doi:10.1093/applin/25.1.38

- Guangwei H. (2002) Recent important developments in secondary English language teaching in the People's Republic of China. Language Culture and Curriculum, 15(1), 30-49. DOI: 10.1080/07908310208666631

- Guo, Y. (2014). Chinese EFL learners' comprehension of English idiom variants: Effects of variation type and proficiency level. Chinese Journal of Applied Linguistics, 37(4), 430-450. Doi: https://doi.org/10.1515/cjal-2014-0027

- Hua, X. (2017). Investigating Chinese EFL learners' comprehension of English idioms. Journal of Language Teaching and Research, 8(2), 329-336. DOI: http://dx.doi.org/10.17507/jltr.0802.15 
- Jia-yi, C. L. (2005). "On cloud nine" and "on all fours": which is more transparent? Elements in EFL learners' transparency assumptions. Taiwan Journal of TESOL, 12(2), 41-85. Retrieved from: https://eric.ed.gov/?id=EJ1078932

- Kaisheng, H. (2015). More does not mean better: Frequency and accuracy analysis of lexical bundles in Chinese EFL learners' essay writing. System, 53, 13-23. Doi: https://doi.org/10.1016/j.system.2015.06.011

- Kilroy, K., \& Scalia, J.C. (2015). Teaching idiom and metaphor via poetry in the Chinese EFL classroom. Paper presented at The Asian Conference on Cultural Studies, Kobe, Japan, 225-238. Stable link:

https://www.academia.edu/17837516/Teaching_Idiom_and_Metaphor_via_Poetry_in_the _Chinese_EFL_Classroom

- Lei, Z. (2009) The effect of etymological elaboration on L2 idiom acquisition and retention in an online environment (WebCT) (Master's Thesis). Retrieved from: https://lib.dr.iastate.edu/etd/11126/

- Lianjun, Z. (2008). “A recent history of teaching EFL in China” Essential Teacher, 5(2). Retrieved from: https://www.tesol.org/read-and-publish/journals/other-serial-publications/compleat-links/ compleat-links-volume-5-issue-2-(June-2008)/a-recent-history-of-teaching-efl-in-china

- Liu, J. (2010). Teachers' code-switching to the L1 in EFL Classroom, The Open Applied Linguistics Journal, 3, 10-23, Retrieved from: https://pdfs.semanticscholar.org/60d7/b99e68c8f4710279a16b0005317ca7c66b3d.pdf

- Lu, Q. (2016) A preliminary study of vocational college students' English idioms' learning through translation. Sino-US English Teaching, 13(11), 869-879.

DOI:10.17265/1539-8072/2016.11.006

- Lu, Q. and Wang, J. (2014). On metaphorical features of teachers' directives in college EFL classrooms. Paper presented at CLaSIC (Center for Language Studies International Conference), Singapore, 256 - 276. Retrieved from: http://www.fas.nus.edu.sg/cls/CLaSIC/clasic2014/Proceedings/lu_qiuyun.pdf

- Robinson, P., \& Ellis N.C. (2008) Introduction. In Robinson, P., \& Ellis N.C. (Eds.), Handbook of Cognitive Linguistics and Second Language Acquisition. New York, NY: Routledge.

- Shan-fang, G. (2007). Is idiom comprehension influenced by metaphor awareness of the learners? A case study of Chinese EFL learners. The Linguistics Journal, 3(3), 148- 166. Retrieved from: 
http://citeseerx.ist.psu.edu/viewdoc/download?doi=10.1.1.418.5662\&rep=rep1\&type=pdf \#page $=148$

- Shan-fang, G. (2008). Differential effects of etymological elaboration and rote memorization on idiom acquisition [1] in college EFL learners. The Asian EFL Journal, 10(3), 127-145. Retrieved from:

https://www.elejournals.com/wp-content/uploads/2014/07/September_2008.pdf\#page=12 7

- Shen, H., Wang Y., \& Liu W. (2017) Familiarity in Chinese and English idiom comprehension: An event related potential study from Chinese English learners. Chinese Journal of Applied Linguistics, 40(1), 74-92. DOI: 10.1515/cjal-2017-0005

- Tang, D \& Absalom, D. (1998). Teaching across cultures: Considerations for Western EFL teachers in China. Hong Kong Journal of Applied Linguistics, 3(2), 117-132. Retrieved from: http://citeseerx.ist.psu.edu/viewdoc/download?doi=10.1.1.123.987\&rep=rep1\&type=pdf

- Tsui, S. (2010). The pedagogy of a tertiary level EFL teacher in the PRC. Paper presented at The Third CELC Symposium for English Language Teachers, National University of Singapore, Singapore, 195-208. Retrieved from: http://www.nus.edu.sg/celc/research/books/3rdsymposium/195to208-lam.pdf

- Wang, W \& Xuesong, G. (2008). English language education in China: A review of selected research. Journal of Multilingual \& Multicultural Development, 29(5), 380-399. Doi: $10.1080 / 01434630802147908$

- Wangmeng, J. (2017). From rote learning to motivation: A cognitive-linguistic approach to L2 acquisition of English idioms by Chinese EFL learners. EPiC Series in Language and Linguistics, 2, 25-35. Retrieved from: https://easychair.org/publications/open/Z6G

- Xiaoli, G. (2014). An empirical study on Chinese EFL learners' processing of English animal idioms. Journal of Language Teaching and Research, 5(4) 935-941 Doi: $10.4304 / j 1 t r .5 .4 .935-941$

- Xiuping, L. (2004). An analysis of Chinese EFL learners' beliefs about the role of rote learning in vocabulary learning strategies (doctoral dissertation). Retrieved from http://www.asian-efl-journal.com/xiuping_11-05_thesis.pdf

- Xiuzhi L. (2010). Conceptual metaphor theory and teaching of English and Chinese idioms. Journal of Language Teaching and Research, 1(3), 206-210. doi:10.4304/j1tr.1.3.206-210 
- Yang, X. (2010). Theories analyzing communicative approach in China's EFL classes. Journal of Education and Learning 3(1). Retrieved from: https://pdfs.semanticscholar.org/c5c8/04b6e09b15cb70352d997ab6ce9967a29fa8.pdf

- Yi-chen, C., \& Huei-ling L. (2013) Teaching English idioms as metaphors through cognitive-oriented methods: A case study in an EFL writing class. English Language Teaching, 6(6), 13 - 20. doi:10.5539/elt.v6n6p13

- Ying-Ying, C. (2013a) A study of the relationship between college EFL learners' vocabulary size and idiomatic reading comprehension. NCUE Journal of Humanities, 7, 59-76. Retrieved from: https://core.ac.uk/download/pdf/33185234.pdf

- Ying-Ying, C. (2013b). The investigation of Taiwanese university EFL learners' idiom familiarity and the affecting factors in idiom comprehension. UT Journal of Language and Literature, 10(1), 41-66. Retrieved from: hr.csu.edu.tw/wSite/public/Attachment/f1406692041352.pdf

- Youmei, G. (2011). Cognitive linguistics - inspired empirical study of Chinese EFL teaching. Creative Education, 2(4), 354-362. Doi: 10.4236/ce.2011.24050

- Yu Ren Dong. (2004). Don't keep them in the dark! Teaching metaphors to English language learners. The English Journal. 93(4), 29-35. Stable URL: https://www.jstor.org/stable/4128977

- Zhenhui, R. (1996). Reconciling communicative approaches to the teaching of English with traditional Chinese methods. Research in the Teaching of English, 30(4), 458-471. Retrieved from http://www.jstor.org/stable/40171552 